\title{
Orthodontic Treatment and Pulp Stone Formation: Is There a Relationship?
}

\author{
Yasemin Nur Korkmaz ${ }^{1}$ (), Zeliha Ugur Aydin² (), Burak Sarioglu³ ${ }^{3}$ \\ ${ }^{1}$ Bolu Abant Izzet Baysal University, Faculty of Dentistry, Department of Orthodontics \\ ${ }^{2}$ Bolu Abant Izzet Baysal University, Faculty of Dentistry, Department of Endodontics \\ Ministry of Health, Kirklareli Oral and Dental Health Center
}

Correspondence Author: Yasemin Nur Korkmaz

E-mail: dtyaseminnurkorkmaz@gmail.com

Received: $13.04 .2018 \quad$ Accepted: 13.06 .2018

\begin{abstract}
Objective: The aim of this retrospective study was to evaluate the effect of orthodontic treatment on pulp stone formation.

Methods: The sample population comprised 504 patients (182 males, 312 females) with a mean age of $17.7 \pm 2.9$ years that underwent orthodontic treatment. The pre-treatment and post-treatment panoramic radiographs of the patients were evaluated to detect pulp stones before and after orthodontic treatment. The data were analyzed using Mc Nemar, Chi-square and Fisher Exact tests.

Results: The statistical analysis showed that pulp stone numbers increased significantly after treatment ( $p<0.05)$ and there was no statistically significant difference between the sexes in terms of pulp stone enhancement. The increment of pulp stone numbers after treatment was found to be significantly higher in molars than other teeth $(p<0.05)$. In canine teeth, the increase in pulp stones was statistically higher in females than in males ( $p<0.05$ ).

Conclusion: The results of this study showed that pulp stone numbers increased at different percentages after orthodontic treatment in all tooth groups. It may be concluded that orthodontic treatment can affect calcification metabolism of the pulp and orthodontic forces may increase pulp stone formation.
\end{abstract}

Keywords: Orthodontic treatment, pulp stone, pulpal reaction

\section{INTRODUCTION}

Pulp stones are calcified bodies located in the pulps of healthy, diseased or unerupted teeth (1). Even if it's impacted or unerupted, they can be detected in one or all of a single patient's teeth (2). Pulp stones can either be free or adhered to dentine and one tooth can contain 1 to 12 or more pulp stones (3). They could either be seen as minor particles or major bodies that almost obturate the pulp chamber (1). True pulp stones are formed from dentine and lined by osteoblasts, while false pulp stones are comprised of mineralized degenerated pulp cells (2). Radiographic image of the pulp stone appears as round shaped opacities in the pulp chamber.

Pulp stones are usually visible on radiographs. The frequency of pulp stones seen in human teeth is not clear (4). Varying from $\% 8$ to $\% 90$, the prevalence of pulp stones shows a wide range depending on the study design and examination method (5). While some of the studies showed no difference between males and females $(6,7)$, others demonstrated more pulp stones in women than in men $(8,9)$. The frequency of pulp stones was shown to increase with age (6). They could be detected in all tooth types but mostly in molars (10).
Etiology of pulp stones are not well understood, however, caries, deep restorations, periodontal diseases, chronic inflammation, operative dentistry procedures, ageing, genetics, idiopatic factors and orthodontic treatment were linked with pulp stone formation previously $(1,2,11)$.Pulp stone detection is shown to be a facilitating factor in the early identification of systemic calcifications in a recent study (12). Lovdahl and Gutmann (13) stated that pulp stones are the result of an irritated pulp, which attempts to repair itself.

Pulp stones usually exist in the crown of the tooth rather than the root (14). They usually do not result in pulp diseases or symptoms; however, they may interfere the access to root canals and complicate endodontic treatment. Pulpal calcifications were shown to result in root canal treatment failure and tooth loss (15).

Orthodontic treatment has an impact on dental pulp, alveolar bone and supporting structures. Knowing the effects of orthodontic treatment on the pulp is of crucial importance, because forces formed through orthodontic tooth movement may cause pulpal blood flow changes that induce pulpal complications. Nixon et al. (16) indicated that orthodontic treatment did not have significant permanent effects on dental pulp, while Hamersky et al. (17) stated that the pulp could lose its vitality in consequence of the injury from 
orthodontic forces. Effects of orthodontic extrusive (18) and intrusive (19) orthodontic forces on pulpal tissue have been investigated in previous studies. Orthodontic treatment has been linked to various pulpal reactions like hyperemia, pulpal obliteration due to secondary dentin formation, internal root resorption, hemorrhage and pulpal necrosis (20-22).

The aim of this retrospective study was to evaluate the effect of fixed orthodontic treatment on pulp stones prevalence using pre- and post-orthodontic treatment panoramic radiographs of a Turkish patient group. This will ensure further information to the dental practitioner about the consequences of orthodontic treatment regarding pulp stone formation.

\section{METHODS}

\subsection{Materials and Methods}

The sample population of this retrospective study comprised 504 patients (182 males, 312 females) that underwent orthodontic treatment with fixed appliances at Bolu Abant Izzet Baysal University, Faculty of Dentistry, Department of Orthodontics between the years of 2012-2018. Ethical approval was obtained from the Bolu Abant Izzet Baysal University Clinical Researches Ethics Committee (Date: 22.03.2018, No: 2018/52). The patients were between 12 and 32 years of age at the beginning of the treatment, with a mean age of $17.7 \pm 2.9$ years. The average orthodontic treatment time was $24.5 \pm 3.1$ months. The pre-treatment (TO) and post-treatment (T1) panoramic radiographs of the patients were evaluated to detect pulp stones before and after orthodontic treatment.

All panoramic radiographs were taken by using PaX-Uni3D (Gnatus/Vatech, Suwon, Korea). Pre- and post-treatment radiographic images of the patients were taken as routine orthodontic records. Patients who had high quality panoramic radiographs were included in the study group.

Patients who previously underwent orthodontic treatment, had syndromes and systemic diseases were excluded in order to avoid the impact of these factors on pulp stone formation. Also panoramic radiographs of the patients who had caries, fillings and crowns that prevent the evaluation of the crown pulp were excluded.

Post treatment variables were recorded including gender, age at start of treatment, skeletal classification, tooth extraction, treatment duration and pulp stone formation (present absent).

Central and lateral incisors, canine, premolar and molar teeth were investigated in terms of pulp stones. Teeth with restorations and root canal treatment were not examined. One orthodontist and one endodontist examined all panoramic radiographs under same conditions. After analyzing each panoramic radiograph individually, observers made the final decision when the two observers agreed on dental pulp stone presence.
Randomly selected 100 subjects were assessed by re-evaluating panoramic radiographs at a 2 -week interval by the same observers and the weighted kappa coefficients were highly reproducible for both observers with values of 0.0897 and 0.0912 .

\subsection{Statistical Analysis}

The data were analyzed using Statistical Package for Social Sciences software package (SPSS for Windows, version 22.0, SPSS Inc., Chicago, IL, USA). Frequency distribution of teeth with pulp stones was calculated. Changes in patient numbers that have pulp stones before and after orthodontic treatment were analyzed using Mc Nemar test. Increases in pulp stones according to gender were analyzed with Pearson Chi-square test and Fisher Exact test was used to analyze increases in pulp stones according to gender and tooth type. Differences were considered as significant when $\mathrm{P}<0.05$.

\section{RESULTS}

Panoramic radiographs taken before orthodontic treatment indicated that 36 of the patients had pulp stones before orthodontic treatment, while 160 of the patients had pulp stones on radiographs after orthodontic treatment. The statistical analysis showed that pulp stone numbers increased significantly after treatment $(\mathrm{p}<0.05)$ (Table 1$)$.

Table 1. Changes in patient numbers that have pulp stones before and after orthodontic treatment.

\begin{tabular}{|l|c|c|c|}
\hline \multirow{2}{*}{ Pretreatment } & \multicolumn{2}{|c|}{ Posttreatment } & \multirow{2}{*}{ Total } \\
\cline { 2 - 3 } & Present & Absent & 36 \\
\hline Present & 36 & 0 & 468 \\
\hline Absent & 124 & 344 & 504 \\
\hline Total & 160 & 344 & \\
\hline $\mathbf{p}<0.05$ & & & \\
\hline
\end{tabular}

There was an increase in pulp stone numbers in 108 (33.5\%) female and $52(32.5 \%)$ male patients after treatment, but there was no statistically significant difference between the sexes in terms of pulp stone enhancement ( $p>0.05$ ) (Table 2).

Table 2. Increases in pulp stones according to gender.

\begin{tabular}{|l|c|c|c|}
\hline \multicolumn{4}{|c|}{ Pulp Stones } \\
\hline Female & & Present & Absent \\
& $n$ & 108 & 214 \\
& $\%$ & $33.5 \%$ & $62.2 \%$ \\
\hline Male & $n$ & 52 & 130 \\
& $\%$ & $32.5 \%$ & $71.4 \%$ \\
\hline Total & $n$ & 160 & 344 \\
& $\%$ & $31.7 \%$ & $68.3 \%$ \\
\hline P value & \multicolumn{3}{|c|}{$\mathrm{p}>0.05$} \\
\hline
\end{tabular}

n: Number

The increment of pulp stone numbers after treatment was found to be statistically significantly higher in molars (330 $(65.5 \%))$ and premolars $(56(1.1 \%))$, than in incisors (18 $(3.6 \%))$ and canines $(8(1.6 \%))(p<0.05)$ (Table 3$)$. 
Pulp stone enhancement was detected in the incisor teeth of $14(4.3 \%)$ female and $4(2,2 \%)$ male patients, canine teeth of $8(2.5)$ female and $0(0 \%)$ male patients, premolar teeth of 30 (9.3\%) female and $26(14.3 \%)$ male patients and molar teeth of 204 (63.4\%) female and $126(69.2 \%)$ male patients, but there were no statistically significant differences in terms of pulp increase in incisors, premolars and molars according to sex ( $p>0.05$ ). In canine teeth, the increase in pulp stones was statistically higher in females than in males $(p<0.05)$ (Table 3$)$.

Table 3. Increases in pulp stones according to gender and tooth type.

\begin{tabular}{|c|c|c|c|c|c|c|c|c|c|}
\hline & & \multicolumn{2}{|c}{ Incisive } & \multicolumn{2}{c|}{ Canine } & \multicolumn{2}{c|}{ Premolar } & \multicolumn{2}{c|}{ Molar } \\
\hline & & Present & Absent & Present & Absent & Present & Absent & Present & Absent \\
\hline \multirow{2}{*}{ Female } & $\mathrm{n}$ & 14 & 308 & 8 & 314 & 30 & 292 & 204 & 118 \\
& $\%$ & $4.3 \%$ & $95.7 \%$ & $2.5 \%$ & $97.5 \%$ & $9.3 \%$ & $90.7 \%$ & $63.4 \%$ & $36.6 \%$ \\
\hline \multirow{2}{*}{ Male } & $\mathrm{n}$ & 4 & 178 & 0 & 182 & 26 & 156 & 126 & 56 \\
& $\%$ & $2.2 \%$ & $97.8 \%$ & $0 \%$ & $100 \%$ & $14.3 \%$ & $85.7 \%$ & $69.2 \%$ & $30.8 \%$ \\
\hline \multirow{2}{*}{ Total } & $\mathrm{n}$ & 18 & 486 & 8 & 496 & 56 & 448 & 330 & 174 \\
& $\%$ & $3.6 \%$ & $96.4 \%$ & $1.6 \%$ & $98.4 \%$ & $11.1 \%$ & $88.9 \%$ & $65.5 \%$ & $34.5 \%$ \\
\hline
\end{tabular}

\section{DISCUSSION}

It has been reported that orthodontic force is a controlled trauma and induces molecular changes in cells of periodontal ligament, alveolar bone and pulp-dentin complex (2326). Although it has been investigated in many studies on human and animal models, the tissue interaction between orthodontic forces and dental pulp remains unclear (27).

Histological studies have shown that major changes in the pulp after orthodontic treatment including impaired respiration, vacuolization, circulatory disturbances, hemorrhage, fibro-hyalinosis and even necrosis $(23,27,28)$. Contrary to these findings, some studies reported that changes in the pulp are not long-term and serious after orthodontic force $(29,30)$.

Lazzaretti et al. (27) reported that orthodontic forces cause vascular changes in the pulp and increase the number of pulp calcifications. In accordance with their results, other studies stated that orthodontic forces increase the secretion of various cytokines such as calcitonin gene-related peptide and alkaline phosphatase, which are effective in mineralization metabolism of pulp $(27,31)$.

Therefore, in this study, the effect of orthodontic treatment on pulp stone formation was investigated by comparing pre - and post-treatment panoramic radiographs. Pulp stones are usually seen by coincidence on dental radiographs and may complicate endodontic treatment (32). Histologic and radiographic assessment can be used to determine the pulp stones $(26,33)$. The pulp stone must have reached a certain size $(>200 \mu \mathrm{m})$ and mineralization in order to be detected on the radiographic assessment $(26,34)$. Another disadvantage of the radiographic examination in detecting pulp stones is that the radiograph can be interpreted differently among the observers (35).
Although histologic evaluation is more reliable than radiographic assessment, it has the disadvantage of being an invasive method. Having the advantage of providing precise anatomical details in three dimensions, cone beam computed tomography (CBCT) was used to assess pulp stones in a few recent studies $(36,37)$. However, it cannot be obtained as a routine record in all orthodontic patients due to increased radiation dose. For this reason, the investigation of the pulp stones was conducted on routinely taken panoramic radiographs before and after orthodontic treatment in the present study.

Pulp stone formation was found to be associated with various systemic diseases and syndromes such as type I diabetes, arteriosclerosis, osteitis deformans, cardiovascular diseases, kidney diseases, dentinal displasia, Marfan sydrome, Van der Woude syndrome, Saethre-Cholzen syndrome, Elfin facies syndrome and familial expansile osteolysis (38-41). Therefore, patients with these diseases were not included in this study.

Pulp stone formation has been reported to increase as the subject gets older in various studies investigating the pulp stone incidence $(26,42)$. To exclude the effect of aging on pulp stone formation, patients between the ages of 13 and 32 were included in this study.

To exclude the effect of orthodontic treatment duration on pulp stone formation, a more homogenous group of patients were selected regarding treatment time in this study. Patients who undergone reasonably shorter or longer treatment times than usual were not included. Further studies considering the effect of treatment duration on pulp stone formation should be designed.

The incidence of pulp stone has been investigated in various radiological studies in the literature. The results of studies investigating the incidence of pulp stone in different populations were found to be different $(41,43,44)$. Studies performed at different populations showed that the incidence of pulp stones were found to range from $21 \%$ to $46 \%(34,42)$, while the studies conducted on Turkish population indicated the pulp stone incidence between $4.2 \%$ and $7 \%(26,45)$. In accordance with their results, the incidence of pulp stone before orthodontic treatment was found to be $7.1 \%$ in our study, while the pulp stone incidence increased significantly after orthodontic treatment, reaching a value of $31.7 \%$. This increment in pulp stone formation is consistent with the previous studies that show orthodontic treatment enhances pulpal calcification $(27,46)$

While some studies showed differences in the incidence of pulp stone among genders, others identified no difference $(25,26,44,47,48)$. There was no statistically significant difference in the incidence of pulp stones before orthodontic treatment among genders in this study. Incidence of pulp stone in canines was significantly higher in females after orthodontic treatment, while no significant difference was observed in other teeth. 
It has been shown that the incidence of pulp stones differs according to tooth groups pulp stones have been reported to be most commonly seen in molar teeth in various studies $(34,47,48)$. In the present study, the increment in pulp stone formation after orthodontic treatment was also detected in molar (65\%) teeth. This may be explained by their prolonged exposure to occlusal loads due to being the longest remaining teeth in the mouth.

\section{CONCLUSION}

Our results showed that pulp stone formation increased at different percentages after orthodontic treatment in all tooth groups. The maximum increment was detected in molar teeth. As a result, it may be concluded that orthodontic treatment can affect calcification metabolism of the pulp and orthodontic forces may increase pulp stone formation. Therefore, the clinician should be aware of the pulp stone increment in patients with orthodontic treatment history and perform a detailed radiographic examination before endodontic treatment.

\section{REFERENCES}

[1] Baghdady VS, Ghose LJ, Nahoom HY. Prevalence of pulp stones in a teenage Iraqi group. J Endod 1988; 14:309-311.

[2] Goga R, Chandler N, Oginni A. Pulp stones: a review. Int Endod J 2008; 41:457-468.

[3] Johnson PL, Bevelander G. Histogenesis and histochemistry of pulpal calcification. J Dental Res 1956; 35:714-722.

[4] Berès $F$, Isaac $J$, Mouton L, Rouzière $S$, Berdal $A$, Simon $S$, Dessombz AL. Comparative physicochemical analysis of pulp stone and dentin. J Endod 2016;42: 432-438.

[5] Moss-Salentijn L, Hendricks-Klyvert M. Calcified structures in human dental pulps. J Endod 1988; 14:184-189.

[6] Hamasha AA-H, Darwazeh A. Prevalence of pulp stones in Jordanian adults. Oral Surg Oral Med Oral Pathol Oral Radiol Endod 1998; 86:730-732.

[7] Ranjitkar S, Taylor J, Townsend G. A radiographic assessment of the prevalence of pulp stones in Australians. Aust Dent $J$ 2002; 47:36-40.

[8] Tamse A, Kaffe I, Littner M, Shani R. Statistical evaluation of radiologic survey of pulp stones. J Endod 1982; 8:455-458.

[9] Hill TJ. Pathology of the dental pulp. J Am Dent Assoc 1934; 21:820-844.

[10] White SC, Pharoah MJ. Oral radiology-E-Book: Principles and interpretation. 7th ed. Elsevier Health Sciences; 2014.

[11] Sundell JR, Stanley HR, White CL. The relationship of corona pulp stone formation to experimental operative procedures. Oral Surg Oral Med Oral Pathol Oral Radiol Endod 1968; 25:579-589.

[12] Patil SR. Prevalence of and relationship between pulp and renal stones: A radiographic study. J Oral Biol Craniofac Res 2015; 5:189-192.

[13] Lovdahl PE, Gutmann JL. Problem solving in endodontics: prevention, identification, and management: Mosby; 2011.

[14] Arys A, Philippart C, Dourov N. Microradiography and light microscopy of mineralization in the pulp of undemineralized human primary molars. J Oral Pathol Med 1993;22: 49-53.
[15] Zeng J, Yang F, Zhang W, Gong Q, Du Y, Ling J. Association between dental pulp stones and calcifying nanoparticles. Int J Nanomedicine 2011; 6:109.

[16] Nixon CE, Saviano JA, King GJ, Keeling SD. Histomorphometric study of dental pulp during orthodontic tooth movement. J Endod 1993; 19:13-16.

[17] Hamersky PA, Weimer AD, Taintor JF. The effect of orthodontic force application on the pulpal tissue respiration rate in the human premolar. Am J Orthod 1980; 77:368-378.

[18] Ramazanzadeh BA, Sahhafian AA, Mohtasham N, Hassanzadeh $\mathrm{N}$, Jahanbin A, Shakeri MT. Histological changes in human dental pulp following application of intrusive and extrusive orthodontic forces. J Oral Sci 2009; 51:109-115.

[19] Han G, Hu M, Zhang $Y$, Jiang $H$. Pulp vitality and histologic changes in human dental pulp after the application of moderate and severe intrusive orthodontic forces. Am J Orthod Dentofacial Orthop 2013; 144:518-522.

[20] Barwick PJ, Ramsay DS. Effect of brief intrusive force on human pulpalblood flow. Am J Orthod Dentofacial Orthop 1996; 110:273-279.

[21] Wong V-S, Freer TJ, Joseph BK, Daley TJ. Tooth movement and vascularity of the dental pulp: a pilot study. Aust Orthod J 1999; 15:246.

[22] McDonald F, Pitt Ford T. Blood flow changes in permanent maxillary canines during retraction. Eur J Orthod 1994; 16:1-9.

[23] Javed F, Al-Kheraif AA, Romanos EB, Romanos GE. Influence of orthodontic forces on human dental pulp: a systematic review. Arch Oral Biol 2015; 60:347-356.

[24] Han G, Hu M, Zhang Y, Jiang H. Pulp vitality and histologic changes in human dental pulp after the application of moderate and severe intrusive orthodontic forces. Am J Orthod Dentofacial Orthop 2013; 144:518-522.

[25] Sener S, Cobankara FK, Akgunlu F. Calcifications of the pulp chamber: prevalence and implicated factors. Clin Oral Investig 2009; 13:209-215.

[26] Gulsahi A, Cebeci Al, Ozden S. A radiographic assessment of the prevalence of pulp stones in a group of Turkish dental patients. Int Endod J 2009; 42:735-739.

[27] Lazzaretti DN, Bortoluzzi GS, Torres Fernandes LF, Rodriguez R, Grehs RA, Martins Hartmann MS. Histologic evaluation of human pulp tissue after orthodontic intrusion. J Endod 2014; 40:1537-1540.

[28] Oppenheim A. Biologic orthodontic therapy and reality. Angle Orthod 1936; 6:69-116.

[29] Anstendig HS, Kronman JH. A histologic study of pulpal reaction to orthodontic tooth movement in dogs. Angle Orthod 1972; 42:50-55.

[30] Proffit WR, Fields Jr HW, Sarver DM. Contemporary orthodontics. 5th ed. Elsevier Health Sciences; 2014.

[31] Caviedes-Bucheli J, Moreno JO, Ardila-Pinto J, Del ToroCarreno HR, Saltarin-Quintero H, Sierra-Tapias CL, MaciasGomez F, Ulate E, Lombana-Sanchez N, Munoz HR. The effect of orthodontic forces on calcitonin gene-related peptide expression in human dental pulp. J Endod 2011; 37:934-937.

[32] McCabe PS, Dummer PM. Pulp canal obliteration: an endodontic diagnosis and treatment challenge. Int Endod J 2012;45: 177-197.

[33] Ninomiya $M$, Ohishi M, Kido J, Ohsaki $Y$, Nagata $T$. Immunohistochemical localization of osteopontin in human pulp stones. J Endod 2001; 27:269-272. 
[34] Ranjitkar S, Taylor JA, Townsend GC. A radiographic assessment of the prevalence of pulp stones in Australians. Aust Dent $J$ 2002; 47:36-40.

[35] Deva V, Mogoanta L, Manolea H, Panca OA, Vatu M, Vataman M. Radiological and microscopic aspects of the denticles. Rom J Morphol Embryol 2006; 47:263-268.

[36] da Silva EJNL, Prado MC, Queiroz PM, Nejaim Y, Brasil DM, Groppo FC, Haiter-Neto F. Assessing pulp stones by cone-beam computed tomography. Clin Oral Investig 2017; 21:2327-2333.

[37] Hsieh C-Y, Wu Y-C, Su C-C, Chung M-P, Huang R-Y, Ting P-Y, Lai C-K, Chang KS, Tsai Y-WC, Shieh Y-S. The prevalence and distribution of radiopaque, calcified pulp stones: A conebeam computed tomography study in a northern Taiwanese population. J Dent Sci 2018;13.2:138-144.

[38] Pettiette MT, Zhong S, Moretti AJ, Khan AA. Potential correlation between statins and pulp chamber calcification. J Endod 2013; 39:1119-1123.

[39] Edds AC, Walden JE, Scheetz JP, Goldsmith LJ, Drisko CL, Eleazer PD. Pilot study of correlation of pulp stones with cardiovascular disease. J Endod 2005; 31:504-506.

[40] Bauss O, Neter D, Rahman A. Prevalence of pulp calcifications in patients with Marfan syndrome. Oral Surg Oral Med Oral Pathol Oral Radiol Endod 2008; 106:56-61.
[41] Goga R, Chandler NP, Oginni AO. Pulp stones: a review. Int Endod J 2008; 41:457-468.

[42] Tamse A, Kaffe I, Littner MM, Shani R. Statistical evaluation of radiologic survey of pulp stones. J Endod 1982; 8:455-458.

[43] Ramazanzadeh BA, Sahhafian AA, Mohtasham N, Hassanzadeh $N$, Jahanbin A, Shakeri MT. Histological changes in human dental pulp following application of intrusive and extrusive orthodontic forces. J Oral Sci 2009; 51:109-115.

[44] Kannan S, Kannepady SK, Muthu K, Jeevan MB, Thapasum A. Radiographic assessment of the prevalence of pulp stones in Malaysians. J Endod 2015; 41:333-337.

[45] Uslu O, Akcam MO, Evirgen S, Cebeci I. Prevalence of dental anomalies in various malocclusions. Am J Orthod Dentofacial Orthop 2009; 135:328-335.

[46] Subay RK, Kaya H, Tarim B, Subay A, Cox CF. Response of human pulpal tissue to orthodontic extrusive applications. J Endod 2001; 27:508-511.

[47] Sisman $Y$, Aktan AM, Tarim-Ertas E, Ciftci ME, Sekerci AE. The prevalence of pulp stones in a Turkish population. A radiographic survey. Med Oral Patol Oral Cir Bucal 2012; 17:212-217.

[48] al-Hadi Hamasha A, Darwazeh A. Prevalence of pulp stones in Jordanian adults. Oral Surg Oral Med Oral Pathol Oral Radiol Endod 1998; 86:730-732. 